\title{
MEASUREMENT OF RESIDUAL STRESSES AND TOUGHNESS IN Ti-6AI-4V MATERIAL PRODUCED BY LASER BEAM MANUFACTURING
}

\author{
Olivier Quénard ${ }^{1, a}$, Olivier Dorival ${ }^{1,2}$, Philippe Guy $^{1}$ and Kevin Brethome ${ }^{3}$ \\ ${ }^{1}$ Icam, 75 av. de Grande Bretagne 31076 Toulouse, France \\ ${ }^{2}$ Université de Toulouse, Institut Clément Ader UMR CNRS 5312, INSA/UPS/ISAE/Mines Albi, 3 rue Caroline Aigle \\ F-31400 Toulouse, France \\ ${ }^{3}$ Centre National d'Études Spatiales, 18 av. Edouard Belin 31401 Toulouse, France
}

\begin{abstract}
This study deals with the measurement of residual stress by the hole drilling method in Ti-6Al-4V samples obtained by Laser Beam Manufacturing after stress relieving. Indeed, it was of high interest to check the efficiency of such a thermal post-treatment. The influence of the orientation of both the sample and the notch is evaluated from a toughness point of view, and the obtained values are compared to that of similar parts submitted to Hot Isostatic Pressing after stress relief treatment. A more isotropic behaviour were detected on the HIPed samples (with respect to that of the stress relieved ones) with a higher average value. This development is discussed from both residual stress and microstructural points of view.
\end{abstract}

\section{Introduction}

For a few decades, additive layer manufacturing (ALM) appeared as a way of revolutionizing both the design possibilities and manufacturing standards. Now it has started to be used in space, aeronautical and automotive applications. Nevertheless, for each alloy, various parameters can modify the mechanical properties, such as the technique used (Laser Beam Manufacturing (LBM), Electron Beam Manufacturing (EBM), etc.), the manufacturing parameters, the heat post-treatment, powder characteristics, the loading orientation, etc., and very little data, furthermore with large scatter, can be detected in open literature.

This paper is related to the Laser Beam Manufacturing technique dedicated to Ti-6Al-4V which is increasingly being used in aerospace industries. A lot of work for that has been done to investigate the relationship between the process, the microstructure and mechanical properties for LBM shed light on the influence of thermal treatment [1-3] or the building orientation [4-6]. Several other papers dealt with the fatigue properties [7-8]. However, to the authors' knowledge, only a few papers have focused on the fracture toughness of ALM Ti-6Al-4V [7-12], although this is a key point in the damage tolerance approach.

In a previous paper [13], we presented tensile characteristics (Young modulus, Yield Stress, Ultimate Tensile Stress and Elongation) obtained for both stress relieved and post-Hot Isostatic

\footnotetext{
${ }^{\mathrm{a}}$ Corresponding author : olivier.quenard@icam.fr
} 
Pressed Ti-6Al-4V LBM samples, versus the loading orientation. Microstructural and surface fracture observations allowed the changes in the measured properties to be explained. Nevertheless, as outlined in this paper, residual stresses due to thermal conditions during manufacturing in some samples led to cracking in the as-built samples (before any thermal relief post treatment), inducing the inability to perform any mechanical test. The present study focuses on the measurement of residual stresses in the relieved Ti-6Al-4V LBM samples. The aim of this project is to determine if this soft heat treatment wholly releases samples free from thermal stresses. The toughness of the samples are presented for all cases of orientation and post-heat treatment. All these data were requested by the CNES in order to better design and size parts which would then be interesting to produce by LBM for weight saving in spatial applications.

\section{Sample preparation and testing methods}

\subsection{Materials and manufacturing parameters}

All the Ti-6Al-4V specimens were manufactured during a single batch in order to avoid any problem of reproducibility of the manufacturing parameters. By using a Ti-6Al-4V powder from Advanced Powders and Coatings, with 15-45 $\mu \mathrm{m}$ particle size, the samples were manufactured in an EOS M280 machine using a 1060-1100 $\mu \mathrm{m}$ wavelength laser. Successive layers were $60 \mu \mathrm{m}$ thick. After a stress relief treatment on the base platform $\left(670^{\circ} \mathrm{C} / 5 \mathrm{~h}\right)$ to release residual stresses, half the specimens were submitted to an additional Hot Isostatic Pressing (HIP) process $\left(920^{\circ} \mathrm{C} / 2 \mathrm{~h} / 1020 \mathrm{bars}\right)$.

\subsection{Preparation for residual stress and toughness tests}

For residual stress measurements, in order not to change the massiveness of the obtained samples (potentially leading to change in heat transfer and thus in the cooling rate after laser scanning) we chose to manufacture samples with dimensions (cubes of $20 \times 20 \times 20 \mathrm{~mm}^{3}$ ) similar to those for toughness test specimens (at least from a width point of view). For the toughness tests, the size of produced samples was $45 \times 45 \times 20 \mathrm{~mm}^{3}$.

After the ALM process and the corresponding thermal treatments, toughness specimens were machined to get the corresponding dimensions (32 mm width, according to ASTM E399 [14] norm (W32-B16)) and to create the notch along the expected direction (see Figure 1). Five samples were produced for each combination of orientation/thermal treatment.

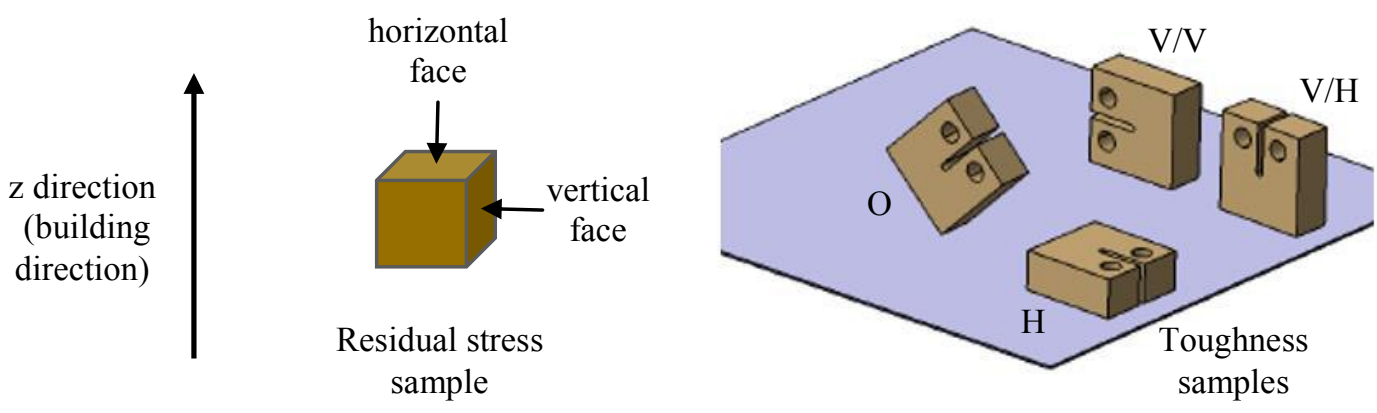

Figure 1. Orientations of the samples for both toughness (left) and residual stress (right) tests

For residual stress preparation, samples were gently manually polished in order to eliminate the surface oxide layer, and to allow good bonding with the strain gauge rosettes. Measurements were performed on both the horizontal and vertical surfaces (see Figure 1). 


\subsection{Residual stress and toughness tests set-up}

Residual stresses were measured by the Hole Drilling Method (HDM). After bonding a 3 -grid strain gauge rosette (type A) on the surface of the sample, this test consisted in measuring the resulting strain while gradually drilling a hole of $1.6 \mathrm{~m}$ in diameter, confirming with ASTM E387 [15]. The drilling was performed by steps of $50 \mu \mathrm{m}$, until $1 \mathrm{~mm}$ in depth was reached.

The three measured strain curves (see Figure 2), using Young Modulus and Poisson ratio measured (119 GPa and 0.33 respectively), lead to the determination of both the in-plane stress tensor $\left(\sigma_{\mathrm{x}}, \sigma_{\mathrm{y}}\right.$ and $\left.\tau_{\mathrm{xy}}\right)$ and the equivalent Von Mises stress.

Toughness tests were performed on an Instron electromechanical testing machine of UTM-EM type, using Bluehill 3.35 software. Apparatus involved a 2525-801 type $100 \mathrm{kN}$ Instron load cell and a 2670-130 Crack Opening Displacement Gauge from Instron. Tests were performed following the ASTM E399 recommendation. Load rate of $0.33 \mathrm{kN} / \mathrm{s}$ was used up to the global failure of the specimen.
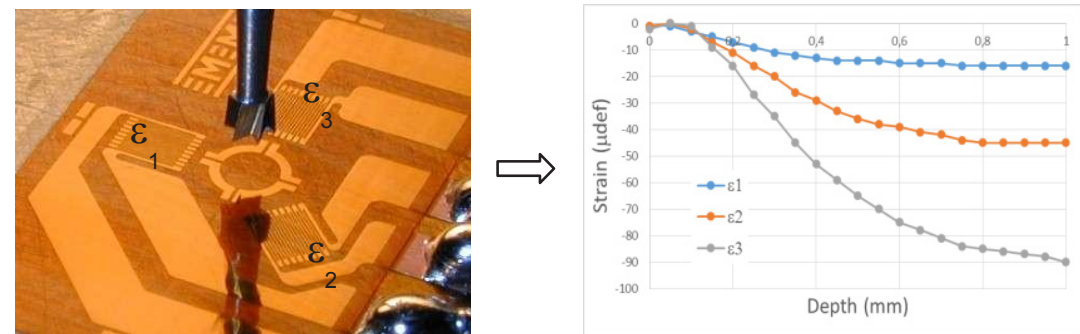

Figure 2. Presentation of the HDM (left) and obtained strain plotting along the 3 directions (right) versus the hole depth

\section{Results}

\subsection{Residual stress}

The raw data obtained on the horizontal surface of the relieved Ti-6Al-4V sample are presented in Figure 3-a. The calculated results reveal, on the one hand, that the stress along the $\mathrm{X}$ and $\mathrm{Y}$ directions presents very similar distributions (see Figure 3-b), while it seems that there is no shear stress. As a first conclusion, one can say that the tested sample has an isotropic horizontal in-plane behaviour, which can easily be explained by the fact that the laser manufacturing is performed by changing the scanning angle from layer to layer. Moreover, the positive values for the $\mathrm{X}$ and $\mathrm{Y}$ stresses correspond to the tensile stresses. On the other hand, one can note through the Von Mises stress curve (see Figure 3 -c) that the residual stress in the material is superficially concentrated in the first $400 \mu \mathrm{m}$, with a maximum value centred around 150-200 $\mu \mathrm{m}$. This maximum residual stress level is lower than 40 $\mathrm{MPa}$, meaning that it is almost negligible. It seems that there is no residual stress after $250 \mu \mathrm{m}$ depth. 

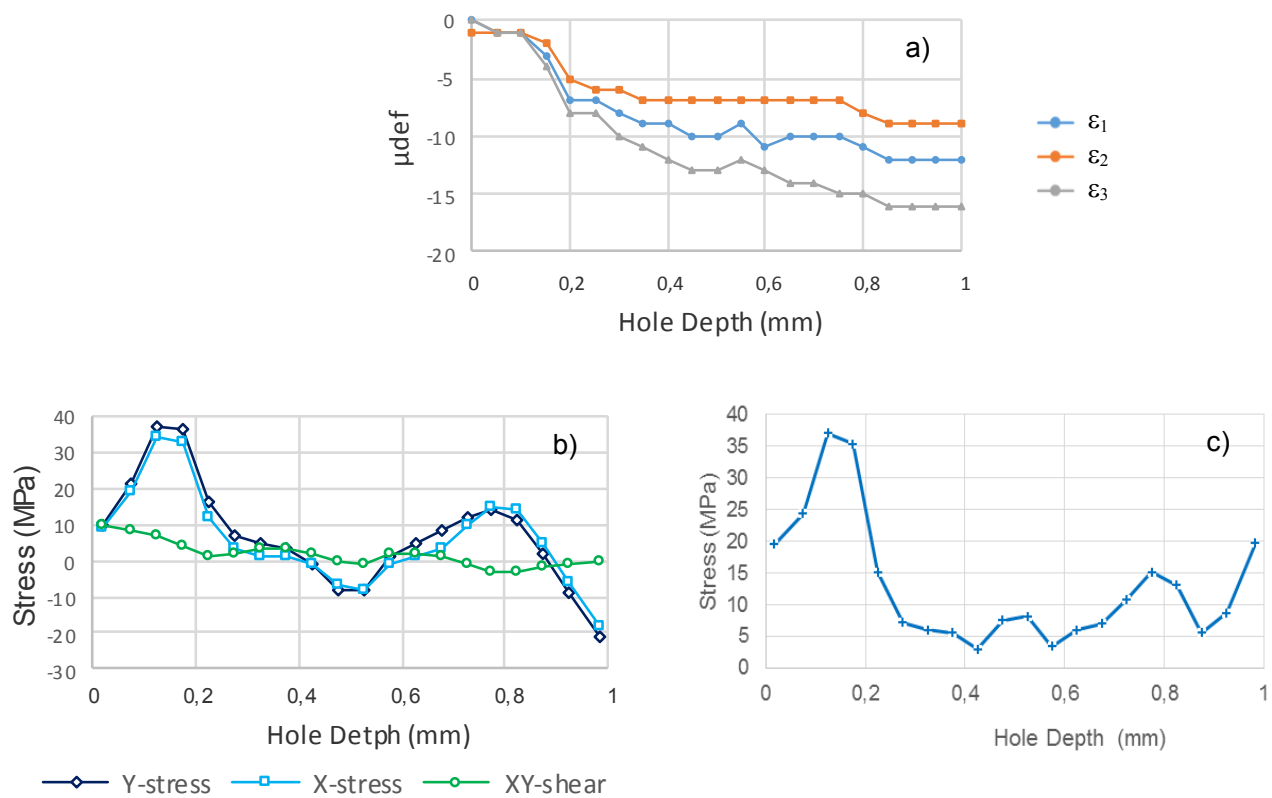

Figure 3. Strain curves obtained on the horizontal face by the HDM (a), and calculated stress tensor (b) and Von Mises Stress (c)

The results obtained on the vertical surface of the sample show similar curves concerning the $\mathrm{X}$ and Y stresses (see Figure 4-a) with reference to that obtained for the horizontal surface. The negative values measured at the extreme surface indicate a compressive stress, while these values quickly change for positive values representing tensile stresses. The similar stress distributions along the $\mathrm{X}$ and $\mathrm{Y}$ directions also reveal an isotropic vertical in-plane behaviour. The only difference is that a slight sub-superficial shear stress seems to be detected at around $200 \mu \mathrm{m}$ depth, with a value lower than $20 \mathrm{MPa}$.

The calculated Von Mises stress curve presents (see Figure 4-b) a similar shape with reference to that of the horizontal surface. Indeed, only a slight sub-superficial residual stress is detected, the maximum value of which is close to $45 \mathrm{MPa}$, at around $200 \mu \mathrm{m}$ depth. Almost no residual stress is detected after $300 \mu \mathrm{m}$ depth.
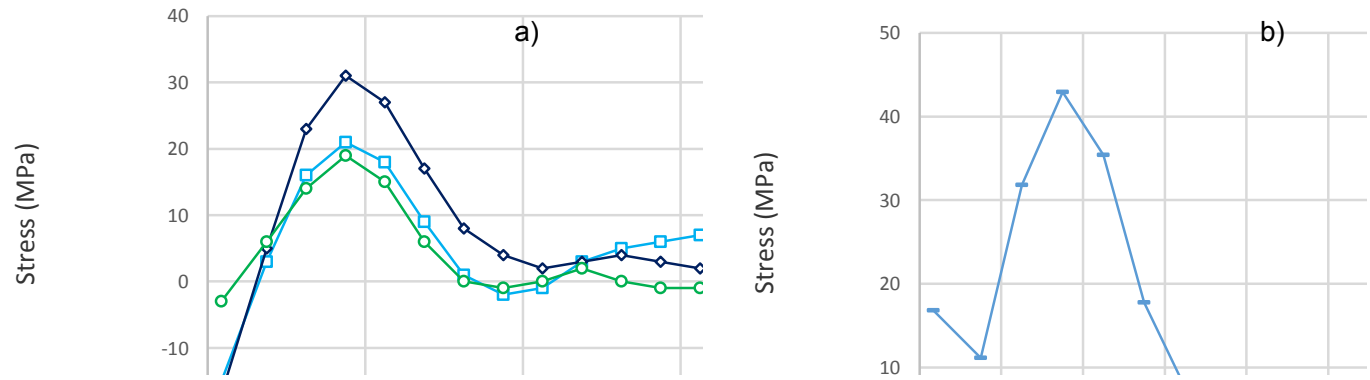

Figure 4. Calculated stress tensor (a) and Von Mises Stress (b) obtained on the vertical face

As a global conclusion for this part, one can say that the relieving heat treatment imposed on the LBM samples is efficient enough to erase almost all internal residual stress in the samples. Only a very slight sub-superficial stress, ranging from between 40 and $50 \mathrm{MPa}$, is detected at around $200 \mu \mathrm{m}$ 
depth. In comparison, much higher values (up to $400 \mathrm{MPa}$ ) have been reported in literature on welded Ti-6Al-4V plates [16].

\subsection{Toughness}

\subsubsection{Stress relieved Ti-6Al-4V}

The results reveal that the orientation was a moderate influence on the measured toughness of the sample (see Figure 5). Indeed, only the $\mathrm{V} / \mathrm{H}$ samples (see orientations in Figure 1) seem to present slightly higher average values $(+17 \%)$ with reference to that of the three other orientations (the average values range between 38 and $46 \mathrm{MPa} \cdot \mathrm{m}^{1 / 2}$ ).

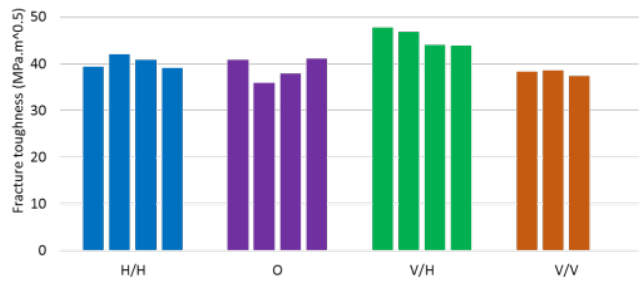

Figure 5. Fracture toughness vs orientation measured on the stress relieved Ti-6Al-4V samples

\subsubsection{HIPed Ti-6Al-4V}

The results for HIPed samples are presented in Figure 6. The fracture toughness of the samples strongly increased ( $+50-60 \%$ depending on the orientation) after Hot Isostatic Pressing, reaching an average value close to $65 \mathrm{MPa} \cdot \mathrm{m}^{1 / 2}$. Moreover, this post-treatment seemed give rise to a more isotropic material, as the slight anisotropy detected previously in the $\mathrm{V} / \mathrm{H}$ direction had almost disappeared.

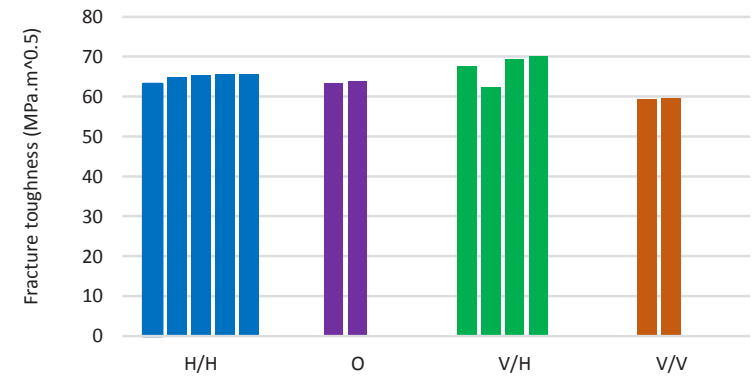

Figure 6. Fracture toughness vs orientation measured on the HIPed Ti-6Al-4V samples

\section{Conclusions and prospects}

As a first conclusion of this study, one can confirm that the stress relieving thermal post-treatment performed on the ALM Ti-6Al-4V samples is efficient enough to reduce internal residual stresses down to negligible values (lower than $40 \mathrm{MPa}$ whatever the orientation of the measurement). Therefore, the difference of mechanical properties, and especially fracture toughness, before and after Hot Isostatic Pressing cannot be attributed, even partially, to residual stress. Only a change in the microstructure [13], changing from fully martensitic (for stress relieved samples) to $\alpha-\beta$ (for HIPed samples) seems to be responsible for the $50-60 \%$ increase in the obtained toughness. 
Nevertheless, the HDM allows residual stress to be measured in only a narrow range of depth (lower than $1 \mathrm{~mm}$ ), while our samples were $16 \mathrm{~mm}$ thick. A similar study could be performed on thinner samples, in order to check the influence of massiveness of the parts on the obtained microstructures and mechanical properties.

\section{References}

1. L. Thijs, F. Verhaeghe, T. Craeghs, J. Van Humbeeck, J.-P. Kruth, Acta Mater, 58, 3303 (2010)

2. L. Facchini, E. Magalini, P. Robotti, A. Molinari, S. Höges, K. Wissenbach, Rapid Prototyping Journal, 16(6), 450 (2010)

3. B. Vrancken, L. Thijs, J.-P. Kruth, J. Van Humbeeck, Journal of Alloys and Compounds, 541, 177 (2012)

4. C. Qiu, N.J.E. Adkins, M.M. Attallah, Materials Science and Engineering: A, 578, 230 (2013)

5. M. Simonelli, Y.Y. Tse, C. Tuck, Materials Science and Engineering: A, 616, 1 (2014)

6. S. Palanivel, A.K. Dutt, E.J. Faierson, R.S. Mishra, Materials Science and Engineering: A, 654, 39 (2016)

7. B. Van Hooreweder, D. Moens, R. Boonen, J.-P. Kruth, P. Sas, Paul, Advanced Engineering Materials, 14(1-2), 92 (2012)

8. D. Greitemeier, F. Palm, F. Syassen, T. Melz, International Journal of Fatigue, 94(2), 211 (2017)

9. V. Cain, L. Thijs, J. Van Humbeeck, B. Van Hooreweder, R. Knutsen, Additive Manufacturing, 5, 68 (2015)

10. P. Edwards, M. Ramulu, Fatigue \& Fracture of Engineering Materials \& Structures, 38(10), 1228$1236(2015)$

11. M. Seifi, M. Dahar, R. Aman, O. Harrysson, J. Beuth, JOM, 67(3), 597 (2015)

12. P. Edwards, A. O’Conner, M. Ramulu, J. Manuf. Sci. Eng, 135(6), 061016 (2013)

13. O. Quénard, O. Dorival, Ph. Guy, A. Votié, K. Brethome, ECSSMET, European Conference on Spacecraft Structures Materials and Environmental Testing (2016)

14. ASTM E8 / E8M-15a, ASTM International (2015)

15. ASTM E837, ASTM International (2001)

16. C. Casavola, C. Pappalettere, extras.springer.com (2007) 